http://jmscr.igmpublication.org/home/ ISSN (e)-2347-176x ISSN (p) 2455-0450 crossref DOI: https://dx.doi.org/10.18535/jmscr/v9i4.14

\title{
Comparing HO and Travis Criteria in Acute Severe Ulcerative Colitis - In a Tertiary Care Centre, South India
}

\author{
Authors \\ L. Sujatha ${ }^{1}$, Caroline Selvi ${ }^{2}$, Premkumar $^{3}$, A. Chezhian ${ }^{4}$, R. Murali ${ }^{5}$ \\ ${ }^{1}$ Resident, Madras Medical College, The Tamilnadu Dr MGR University, Chennai \\ ${ }^{2}$ Professor, Madras Medical College, Chennai \\ ${ }^{3}$ Associate Professor, Madras Medical College, Chennai \\ ${ }^{4,5}$ Assistant Professor, Madras Medical College, Chennai
}

\begin{abstract}
Aim: To compare Ho score with Travis score in predicting steroid responsiveness in acute severe ulcerative colitis.

Methods and Material: Our study is a prospective observational study including all patients who got admitted in Institute of medical gastroenterology, Rajiv Gandhi Government General Hospital, Chennai, between January 2019 and December 2019 with acute severe ulcerative colitis as per True love witts score.

Results: Among 64, 55 were male and 9 were female. Mean age of patients is 32 years (range 16-45 years). Day 3 Travis score was high in 16 patients (25\%) and low in 48 patients (75\%). 48 patients (75\%) were steroid responsive and 16 patients $(25 \%)$ were steroid non-responsive who received second line therapy in the form of anti-TNF agents. All 4 patients with high Ho score on day 3 were steroid non-responders, 6 patients with intermediate Ho score were steroid responsive and 12 patients with intermediate Ho score on day 3 were steroid non-responders. Ho score of $\geq 2.5$ has sensitivity of $62.5 \%$ and specificity of $100 \%$ in predicting steroid responsiveness.

Conclusion: We conclude that in acute severe ulcerative colitis, patients with high Travis or the Ho scores are more likely to be resistant to IV steroids. In anti-TNF era, the risk of surgery in those high risk patients is lower than previously reported.
\end{abstract}

Keywords: Acute severe ulcerative colitis, Travis score, Ho score, steroid refractory ulcerative colitis.

\section{Introduction}

Ulcerative colitis (UC) is a chronic inflammatory bowel disease that is characterized by hematochezia, diarrhea, tenesmus, fever and constitutional symptoms $^{[1]}$. About $20 \%$ of patients with UC will develop an episode of acute severe ulcerative colitis (ASUC) and $15-25 \%$ will have a severe exacerbation that will require admission at some point $^{[2]-[4]}$.

\section{Case Definition}

\section{Acute Severe Ulcerative Colitis}

Acute severe ulcerative colitis is commonly diagnosed using Truelove and Witts score (TABLE 1). Intravenous steroids are the mainstay of therapy in acute severe flare. The usual dose regimen is methylprednisolone $20 \mathrm{mg}$ or hydrocortisone 100 $\mathrm{mg}$, both given every 6 to 8 hours IV. The response to intravenous steroids should be best assessed by the third day. Overall, response rates to 
corticosteroids reach $65-69 \%{ }^{[5][6]}$. In non-responders, treatment options including ciclosporin, infliximab, tacrolimus or surgery should be considered ${ }^{[7]}$.

Table 1. Truelove and Witts Score ${ }^{[8]}$

\begin{tabular}{|c|c|c|c|}
\hline & MILD & MODERATE & SEVERE \\
\hline BLOODY STOOLS & $\begin{array}{c}\leq 4 \text { stools/ } \\
\text { day }\end{array}$ & \multirow{5}{*}{$\begin{array}{c}\text { Intermediate } \\
\text { between mild } \\
\text { and severe }\end{array}$} & $\begin{array}{c}\geq 6 \text { stools/ day } \\
\text { AND }\end{array}$ \\
\hline TEMPERATURE & $<37.5^{\circ} \mathrm{C}$ & & $>37.8^{\circ} \mathrm{C}$ \\
\hline HEART RATE & $<90 / \min$ & & $>90 / \mathrm{min}$ \\
\hline HEMOGLOBIN & $>11.5 \mathrm{~g} / \mathrm{dl}$ & & $<10.5 \mathrm{~g} / \mathrm{dl}$ \\
\hline ESR & $<20 \mathrm{~mm} / \mathrm{hr}$ & & $>30 \mathrm{~mm} / \mathrm{hr}$ \\
\hline
\end{tabular}

\section{Steroid Refractory Acute Severe Ulcerative Colitis}

A frequency $>$ eight/day, or between three and eight together with a CRP $>45 \mathrm{mg} / \mathrm{l}$ on Day 3, predicted colectomy in $85 \%$ during that admission: known as the Oxford Travis Criteria ${ }^{[9]}$, which is most commonly used. There are many other scores to predict steroid non-responsiveness. While original Travis score predicts risk for colectomy, G.T. Ho et al. designed another simple score to detect patients who respond from early second-line therapy ${ }^{[10]}$.

Table 2: HO Score ${ }^{[10]}$ :

\begin{tabular}{|l|c|}
\hline Variables & Score \\
\hline Mean stool frequency & \\
\hline$<4$ & 0 \\
\hline $4-6$ & 1 \\
\hline $6-9$ & 2 \\
\hline$>9$ & 4 \\
\hline Colonic dilatation $>5.5 \mathrm{~cm}$ & 4 \\
\hline Hypoalbuminemia $<30 \mathrm{~g} / \mathrm{L}$ & 1 \\
\hline
\end{tabular}

HO score ranges from 0 to 9 . It is classified as low(score 0-1), intermediate- (score 2-3) and high- risk (score $\geq 4$ ) groups with medical failure rates of $11 \%, 45 \%$ and $85 \%$ respectively ${ }^{[10]}$.

\section{Aim}

To compare Ho score with Travis score in predicting steroid responsiveness in acute severe ulcerative colitis

\section{Materials and Methods}

A prospective observational study including all patients who got admitted in Institute of medical gastroenterology, Rajiv Gandhi Government General Hospital, Chennai, between January 2019 and December 2019 with acute severe ulcerative colitis as per True love witts score.

\section{Inclusion Criteria}

All adults with ulcerative colitis (The diagnosis of UC was confirmed on clinical, radiological and histological criteria) and has acute severe ulcerative colitis according to Truelove Witts score.

\section{Exclusion Criteria}

a. Patients with toxic megacolon at admission

b. Patients who are steroid dependent/ intolerant

c. Patients with acute flare due to infections

d. Patients who do not sign the consent

Steroid responders are those who got discharged from hospital without initiation of further treatment for active UC, either medical or surgical. Steroid non-responders are who required further medical or surgical treatment for active UC as they had not had a sufficient response to IV steroids. Steroid nonresponders are then evaluated for active or latent infections including tuberculosis. They were treated with second line drugs (anti-TNF agents) or surgery as indicated.

\section{Statistical Analysis}

Data analysis was done using SPSS 16.0 version. Data were presented as mean and standard deviation if the variables are continuous in nature and as percentages if the variables are categorical in nature. Chi-square test was done to find out the association between the categorical variables. ROC analysis was done and Youden index was used to identify the cut off values at which $\mathrm{HO}$ score has high sensitivity and specificity in predicting steroid resistance. Kappa test was done to assess the agreement between HO score and TRAVIS score.

\section{Results}

A total of 64 patients admitted in the study period had acute severe ulcerative colitis according to Truelove Witts score. Among 64, 55 were male and 9 were female. Mean age of patients is 32 years (range 16-45 years). Majority of the patients had left sided colitis (63\%), followed by pancolitis (34\%), then proctitis (3\%). Day 3 Travis score was high in 16 patients and low in 48 patients. Day 3 Ho score was high in 4 patients, intermediate in 18 patients, low in 42 patients. 


\section{JMSCR Vol||09||Issue||04||Page 81-85||April}

Table 3: Patient Characteristics on Admission

\begin{tabular}{|l|c|c|c|c|}
\hline Variables & Mean & $\begin{array}{c}\text { Standard } \\
\text { Deviation }\end{array}$ & Minimum & Maximum \\
\hline FEVER (F) & 98.34 & .72 & 98.00 & 101.00 \\
\hline $\begin{array}{l}\text { PULSE RATE (per } \\
\text { min) }\end{array}$ & 98.00 & 13.35 & 78.00 & 137.00 \\
\hline $\begin{array}{l}\text { Hemoglobin at } \\
\text { admission (g/dl) }\end{array}$ & 8.64 & 1.11 & 5.00 & 10.00 \\
\hline $\begin{array}{l}\text { Albumin at admission } \\
\text { (g/dl) }\end{array}$ & 2.90 & .43 & 1.80 & 3.50 \\
\hline $\begin{array}{l}\text { Number of stools on } \\
\text { day3 }\end{array}$ & 7.69 & 2.27 & 5.00 & 12.00 \\
\hline CRP (mg/l) ON DAY3 & 36.39 & 13.73 & 15.00 & 89.00 \\
\hline
\end{tabular}
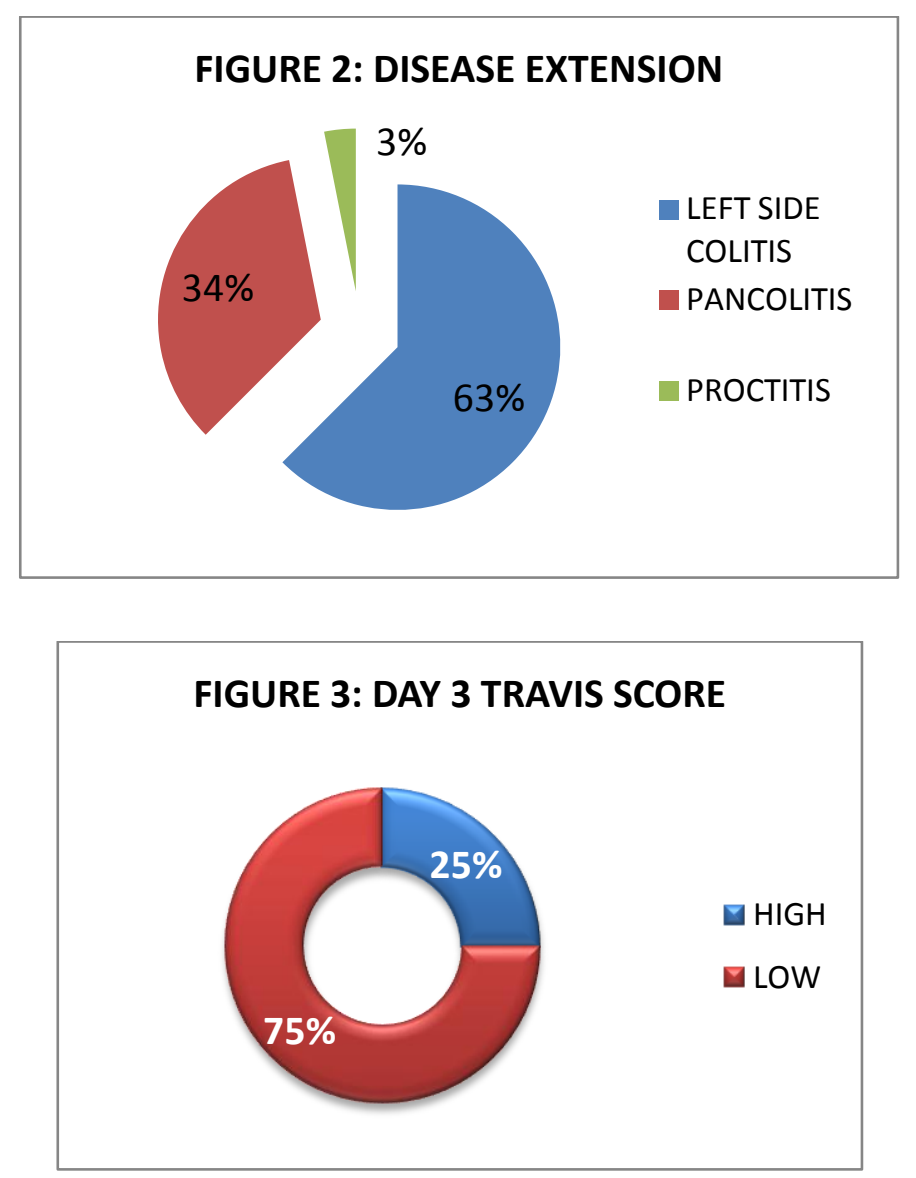

Among 64, 48 patients (75\%) were steroid responsive and 16 patients $(25 \%)$ were steroid nonresponsive who received second line therapy in the form of anti-TNF agents. Out of 64 patients, only 6 patients underwent surgery and the others were successfully treated with medical therapy.
FIGURE 4: DAY 3 HO SCORE

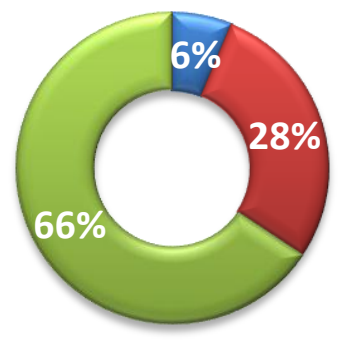

$\square \mathrm{HIGH}(4-9)$

$\square$ INTERMEDIATE

(2-3)

$\square \operatorname{LOW}(0-1)$

Among 16 patients with high Travis score, 4 had high Ho score, 12 had intermediate Ho score and none had low Ho score. Out of remaining 48 patients with low Travis score, 6 had intermediate Ho score and 42 had low Ho score.

\section{FIGURE 5: COMPARISON BETWEEN TRAVIS AND HO SCORE}

-HO-HIGH HO-INTERMEDIATE HO-LOW

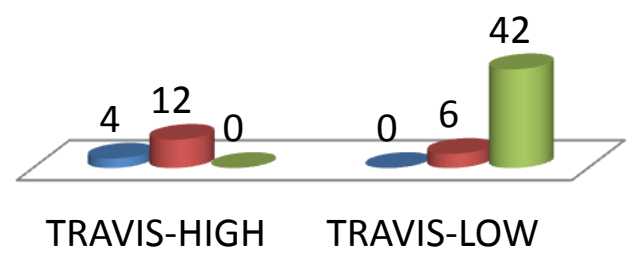

Table 4: Patient Variables, Disease Characteristics, Treatment Response Comparison between 2 Scores

\begin{tabular}{|c|c|c|c|c|c|c|}
\hline \multirow{2}{*}{\multicolumn{2}{|c|}{ Variables }} & \multicolumn{2}{|c|}{ Travis Day3 } & \multicolumn{3}{|c|}{ Ho Score Day 3} \\
\hline & & \multirow{2}{*}{$\begin{array}{c}\text { High } \\
100.0 \%\end{array}$} & \multirow{2}{*}{$\begin{array}{c}\text { Low } \\
81.2 \%\end{array}$} & \multirow{2}{*}{$\begin{array}{c}\text { High } \\
100.0 \%\end{array}$} & \multirow{2}{*}{$\begin{array}{c}\begin{array}{c}\text { Inter } \\
\text { Mediate }\end{array} \\
94.4 \%\end{array}$} & \multirow{2}{*}{$\begin{array}{c}\text { Low } \\
81.0 \%\end{array}$} \\
\hline & Male & & & & & \\
\hline Sex & Female & 0 & $18.8 \%$ & 0 & $5.6 \%$ & $19.0 \%$ \\
\hline \multirow{4}{*}{$\begin{array}{l}\text { Age } \\
\text { Group }\end{array}$} & $</=20$ & 0 & $6.2 \%$ & 0 & 0 & $7.1 \%$ \\
\hline & $21-30$ & $37.5 \%$ & $37.5 \%$ & $25.0 \%$ & $44.4 \%$ & $35.7 \%$ \\
\hline & $31-40$ & $62.5 \%$ & $45.8 \%$ & $75.0 \%$ & $55.6 \%$ & $45.2 \%$ \\
\hline & $41-50$ & 0 & $10.4 \%$ & 0 & 0 & $11.9 \%$ \\
\hline \multirow{4}{*}{$\begin{array}{l}\text { Disease } \\
\text { Extent }\end{array}$} & $\begin{array}{c}\text { Left Side } \\
\text { Colitis }\end{array}$ & $75.0 \%$ & $58.3 \%$ & $75.0 \%$ & $61.1 \%$ & $61.9 \%$ \\
\hline & Pancolitis & $25.0 \%$ & $29.2 \%$ & $25.0 \%$ & $27.8 \%$ & $28.6 \%$ \\
\hline & $\begin{array}{c}\text { Extensive } \\
\text { Colitis }\end{array}$ & 0 & $8.3 \%$ & 0 & $5.6 \%$ & $7.1 \%$ \\
\hline & Proctitis & 0 & $4.2 \%$ & 0 & $5.6 \%$ & $2.4 \%$ \\
\hline \multirow{2}{*}{$\begin{array}{l}\text { Endosco } \\
\text { Severity }\end{array}$} & Moderate & $43.8 \%$ & $89.6 \%$ & $100.0 \%$ & $38.9 \%$ & $92.9 \%$ \\
\hline & Severe & $56.2 \%$ & $10.4 \%$ & 0 & $61.1 \%$ & $7.1 \%$ \\
\hline \multirow{2}{*}{$\begin{array}{l}\text { Steroid } \\
\text { Response }\end{array}$} & Yes & 0 & $100.0 \%$ & 0 & $33.3 \%$ & $100.0 \%$ \\
\hline & No & $100.0 \%$ & 0 & $100.0 \%$ & $66.7 \%$ & 0 \\
\hline \multirow{2}{*}{$\begin{array}{l}\text { Anti Tnf } \\
2^{\text {nd }} \text { Line }\end{array}$} & Yes & $100.0 \%$ & 0 & $100.0 \%$ & $66.7 \%$ & 0 \\
\hline & No & 0 & $100.0 \%$ & 0 & $33.3 \%$ & $100.0 \%$ \\
\hline \multirow{2}{*}{ Surgery } & Yes & $37.5 \%$ & 0 & $50.0 \%$ & $22.2 \%$ & 0 \\
\hline & No & $62.5 \%$ & $100.0 \%$ & $50.0 \%$ & $77.8 \%$ & $100.0 \%$ \\
\hline \multirow{2}{*}{ Mortality } & Yes & $6.2 \%$ & 0 & 0 & $5.6 \%$ & 0 \\
\hline & No & $93.8 \%$ & $100.0 \%$ & $100.0 \%$ & $94.4 \%$ & $100.0 \%$ \\
\hline
\end{tabular}


All 4 patients with high Ho score on day 3 were steroid non-responders, 6 patients with intermediate Ho score were steroid responsive and 12 patients with intermediate Ho score on day 3 were steroid non-responders. Based on ROC analysis the cut off value of Ho score to predict steroid response was found to be 2.5. Youden index was used to estimate the cut off value. Ho score of $\geq 2.5$ has sensitivity of $62.5 \%$ and specificity of $100 \%$ in predicting steroid responsiveness.

\section{Figure 6: ROC Curve}

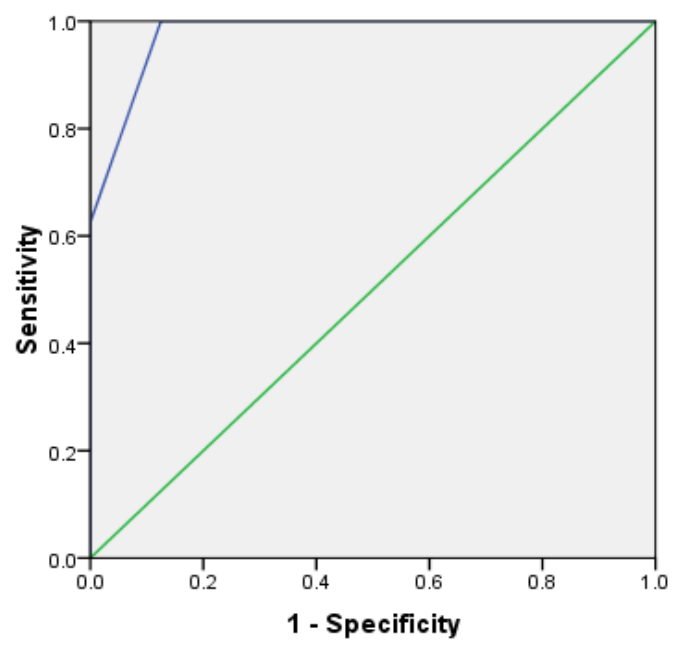

\section{Discussion}

All patients with high Travis score or Ho score were steroid non-responders. In this study, 16 out of 64 did not respond to steroids and required second-line drugs. They were treated with anti-TNF drugs (Infliximab/ Adalimumab). Among 16 who didn't respond to steroids, 6 patients didn't respond to second-line drugs either and required surgery. The steroid resistance rate in our study is $25 \%$, which is slightly lower than previous studies $(40 \%)^{[11][12]}$.

Seah et al. proposes that using the Travis or Ho scores form part of optimal management in acute severe ulcerative colitis ${ }^{[13]}$. We find that both scores are able to identify patients who are at high risk of being refractory to IV steroids requiring second-line drugs or colectomy. In our study the Ho intermediate category does not provide any prognostic benefit over and above the Travis score, potentially making the Travis score more useful clinically due to its simplicity.
Interestingly a recent review by Travis et al. has proposed a more complex treatment algorithm for patients with acute severe ulcerative colitis which incorporates albumin and AXR on day one as predictors of colectomy ${ }^{[14]}$. Thus we decided to compare Travis with Ho score in predicting steroid responsiveness in patients with acute severe ulcerative colitis. In our study we found that though both studies predict steroid responsiveness with high sensitivity, Travis is easier to follow in daily practice. Further studies that include serological, biomarker and genetic data are warranted to improve the diagnostic accuracy of scoring systems in acute severe ulcerative colitis.

\section{Conclusions}

Acute severe colitis is medical emergency. Prompt diagnosis of etiology and aggressive multidisciplinary treatment is associated with low mortality. Travis is simple score that predicts steroid non-responders more accurately. In acute severe ulcerative colitis, patients with high Travis or the Ho scores are more likely to be resistant to IV steroids. In anti-TNF era, the risk of surgery in those high risk patients is lower than previously reported.

\section{References}

1. Dulai, P. S., Levesque, B. G., Feagan, B. G., D'Haens, G., \& Sandborn, W. J. (2015). Assessment of mucosal healing in inflammatory bowel disease. Gastrointestinal endoscopy, 82(2), 246-255.

2. Rice-Oxley, J. M., \& Truelove, S. (1950). Ulcerative colitis course and prognosis. The Lancet, 255(6606), 663-666.

3. Edwards, F. C., \& Truelove, S. C. (1963). The course and prognosis of ulcerative colitis: Part I Short-term prognosis. Gut, 4(4), 299-308.

4. Solberg, I. C., Lygren, I., Jahnsen, J., Aadland, E., Høie, O., Cvancarova, M., ... \& IBSEN Study Group. (2009). Clinical course during the first 10 years of ulcerative colitis: results from a population-based inception 
cohort (IBSEN Study). Scandinavian journal of gastroenterology, 44(4), 431-440.

5. Bernardo, S., Fernandes, S. R., Gonçalves, A. R., Valente, A., Baldaia, C., Santos, P. M., \& Correia, L. A. (2019). Predicting the course of disease in hospitalized patients with acute severe ulcerative colitis. Inflammatory bowel diseases, 25(3), 541-546.

6. Turner, D., Walsh, C. M., Steinhart, A. H., \& Griffiths, A. M. (2007). Response to corticosteroids in severe ulcerative colitis: a systematic review of the literature and a meta-regression. Clinical Gastroenterology and Hepatology, 5(1), 103-110.

7. Harbord, M., Eliakim, R., Bettenworth, D., Karmiris, K., Katsanos, K., Kopylov, U., ... \& Carbonnel, F. (2017). Third European Evidence-based Consensus on Diagnosis and Management of Ulcerative Colitis. Part 2: Current Management (vol 11, pg 769, 2017). Journal of Crohns \& Colitis, 11(12), 1512-1512.

8. Truelove, S. C. (1955). Witts LJ. Cortisone in ulcerative colitis. Final report on a therapeutic trial. $\mathrm{Br}$ Med J, 2, 1041-1048.

9. Travis, S. P., Farrant, J. M., Ricketts, C., Nolan, D. J., Mortensen, N. M., Kettlewell, M. G., \& Jewell, D. P. (1996). Predicting outcome in severe ulcerative colitis. Gut, 38(6), 905-910.

10. Ho, G. T., Mowat, C., Goddard, C. J. R., Fennell, J. M., Shah, N. B., Prescott, R. J., \& Satsangi, J. (2004). Predicting the outcome of severe ulcerative colitis: development of a novel risk score to aid early selection of patients for second- line medical therapy or surgery. Alimentary pharmacology \& therapeutics, 19(10), 1079-1087.

11. Lynch, R. W., Churchhouse, A. M. D., Protheroe, A., Arnott, I. D. R., \& UK IBD Audit Steering Group. (2016). Predicting outcome in acute severe ulcerative colitis: comparison of the Travis and Ho scores using UK IBD audit data. Alimentary pharmacology \& therapeutics, 43(11), 11321141.

12. Järnerot, G., Rolny, P., \& Sandberg-Gertzen, H. (1985). Intensive intravenous treatment of ulcerative colitis. Gastroenterology, 89(5), 1005-1013.

13. Seah, D., \& De Cruz, P. (2016). the practical management of acute severe ulcerative colitis. Alimentary pharmacology \& therapeutics, 43(4), 482-513.

14. Travis, S., Satsangi, J., \& Lémann, M. (2011). Predicting the need for colectomy in severe ulcerative colitis: a critical appraisal of clinical parameters and currently available biomarkers. 